\title{
Knowledge, Attitude and Practice of Emergency Contraceptive among Undergraduate Female College Students: A Cross-Sectional Study
}

\author{
Deressa $\mathrm{JT}^{1 *}$ and Yang $\mathrm{L}^{2}$ \\ ${ }^{1}$ College of Health Sciences, Addis Ababa University, \\ Addis Ababa, Ethiopia \\ ${ }^{2}$ Department of Nursing, Central South University, \\ Changsha, Hunan China \\ *Corresponding author: J embere Tesfaye Deressa, \\ College of Health Sciences, Addis Ababa University, Addis \\ Ababa, Ethiopia
}

Received: April 13, 2021; Accepted: May 01, 2021;

Published: May 08, 2021

\begin{abstract}
Background: Emergency contraceptive is a unique type of family planning methods, which has been available since 1970s and can prevent pregnancy, when used after unprotected sex around the time of ovulation.

Objectives: The main purpose of the study was to investigate the knowledge level, attitude towards and practice of emergency contraceptive among female college students.

Methods: A cross-sectional study design was used and data were collected by structured pre-tested questionnaire that 456 students were randomly selected. Logistic regression analysis was used and $p<0.05$ was considered statistically significant.

Results: About $53.3 \%$ of the study participant's knowledge level were good and $56.1 \%$ of them showed a positive attitude towards emergency contraceptive. Field of study, year of study and awareness were associated with the knowledge level. Age, year of study and sexual behavior were associated with attitudes towards emergency contraceptive. Attitude towards emergency contraceptive and sexual behavior were associated with the utilization of emergency contraceptive.
\end{abstract}

Conclusions: The knowledge level, attitude towards and practice of emergency contraceptives were affected by age, field of study, level of study, awareness and sexual behavior.

Keywords: Attitude; Contraception; Knowledge; Practice; Female college students

\section{Introduction}

Emergency contraceptive is a unique type of family planning methods which has been available since 1970s and can prevent pregnancy, when used after unprotected sex around the time of ovulation $[1,2]$. The consequence of lack of emergency contraceptive both in developed and developing country results and unintended pregnancy which increases abortion throughout the world specifically among adolescents starting from middle school to university students [3]. Family planning services and supplies prevented 187 million unintended pregnancies each year including 60 million unplanned births and 105 million abortions [4]. The WHO and the US Centers for Disease Control and Prevention provide recommendations for use of emergency contraceptive pills, including levonorgestrel and Yuzpe regimen (combined oral contraceptives) and it is a safe way to prevent pregnancy after unprotected sexual intercourse and there are no medical contraindications to its use [5]. There are different types of emergency contraception, and some are more effective than others but obtaining emergency contraception within the recommended time frame was difficult for many women including university students that who have experienced unintended pregnancy, lack contraceptive and reproductive health knowledge [6].

Despite of becoming more open to premarital sex during college period, this is a key time for these students in terms of becoming sexually active and the unplanned pregnancy rate among the participants was $34.03 \%$ [7]. Abortion awakens a mixture of emotions in people generates much controversy in the public health discourse, underlined with significant cultural and moral considerations.

Unintended pregnancy among adolescents represent an important public health challenge in high-income countries, as well as middle- and low-income countries [8]. Many students active in premarital sex lack essential ability of safe sex, and are not able to get aware of contraceptive service [9]. These university students will be the workforce, which leads tomorrow's social development in their country. Safe sex and prevention of unintended pregnancy are necessary measures to maintain good health among university students. Any woman requesting emergency contraceptive after unprotected intercourse should be offered treatment because it is safe for women of all ages [10]. Of all the contraception methods, this emergency contraceptive offers the last chance and used as a bridge to prevent pregnancy which differs from long-term contraceptive measures, and is an extremely effective back-up method in the instance of non-use or failure of regular contraceptives [11]. The study reported that the most effective emergency contraceptive is the Copper Intrauterine Device (IUD), followed by ulipristal acetate and 
levonorgestrel pills [12]. This emergency contraception is especially important for outreach to the 4.5 million women at risk of pregnancy but not using a regular method by providing a link to use of an ongoing contraceptive method [13]. Use of two methods can better prevent pregnancy and the transmission of HIV and other Sexually Transmitted Infections (STIs) compared to single-method use.

One of the key interventions to reduce unintended pregnancy, induced abortion and unsafe abortion as outlined in the national youth strategy is making emergency contraception available for these risky population [14].

The study result found in Ghana concluded that, as increasing awareness about emergency contraceptive among university students is important as they might be benefited from emergency contraceptive if other forms of contraceptives are missed [15].

One interventional study in Nigeria shows, health education plus advance provision of emergency contraceptive pills effectively improved knowledge and attitudes towards emergency contraceptive among female students of tertiary institutions more than health education alone [16].

Lack of knowledge about the risk of unintended pregnancy and having negative attitude towards emergency contraceptive are important factors for the practice of emergency contraceptive. The study by C.T Wang, 2015 summarized that Family planning policy and socioeconomic and demographic factors jointly influence contraceptive choice in china. Even though the Chinese government launched a nationwide family planning program offering birth control methods and family planning services in the 1970s; the use of emergency contraceptive is rare. Types emergency contraceptive available in china are; the levonorgestrel-only regimen consists of either: $1.50 \mathrm{mg}$ of levonorgestrel in a single dose; or two doses of $0.75 \mathrm{mg}$ each, taken up to 12 hours apart.

The combined estrogen-progestin regimen consists of two doses, taken 12 hours apart, of $100 \mathrm{mcg}$ ethinyl estradiol plus $0.50 \mathrm{mg}$ of levonorgestrel. In 2002, China became the first country in which mifepristone was registered for use as an emergency contraceptive. All emergency contraception are available both in governmental and private clinic with costs. The study by Zeng and his colleagues among university students about their attitudes towards sexuality and contraceptive practice showed the level of reproductive health knowledge of modern college students has not reached the stage of adapting to their physical and mental development, and attitude is open, the tolerance of premarital sex is high, and the proportion of premarital sex also increased. This study aimed to investigate the knowledge, attitudes towards and practice of emergency contraceptive and identified factors associated with knowledge, attitude and practice of emergency contraceptive and summarized the significant results.

\section{Materials and Methods}

\section{Study design and period}

This descriptive cross-sectional study design conducted between December 2016 to February 2017 among undergraduate female college students found in the university who were purposively selected and had equal chance to participate on the study.

\section{Sample size calculation}

The sample size was calculated by using a single population proportion formula. To get the maximum sample size for knowledge, attitude and practice of emergency contraceptive was hypothesized to be $50 \%$ and that a non-response rate of $20 \%$, then the required sample was calculated using this formula and total sample size was 462 .

$$
\mathrm{N}=([\mathrm{Z} \alpha / 2])^{2 *} \mathrm{P}(1-\mathrm{p})^{\star} \mathrm{D} /(\mathrm{d})^{2}
$$

\section{Measurement and instrument}

To promote validity and reliability within the study, a number of measures were introduced and taken from a previous published studies on emergency contraception $[17,18]$ and there was some changes according to the local context. The questionnaire was composed of three thematic areas and was checked for Cronbach's alpha for knowledge and attitude for internal consistencies (0.74, 0.81 ) respectively.

Twelve questions were used to measure knowledge of the respondents on emergency contraceptive. If the respondents get the right answer, it was coded as yes " 1 ", if not it was coded as no " 0 ". The respondents' knowledge scores were aggregated, checked for normal distribution. Because of its distribution (was not normally distributed) median was used as cut-off point. Based on the cumulative score, respondents who scored the median value of the total and above, were considered as having had "good knowledge" of emergency contraceptive while those scored below the median were considered as having had "poor knowledge" of emergency contraceptive.

The attitude of study participants towards emergency contraceptive(s) was measured using 14 items rated on five-point Likert scale of six negatively and eight positively stated statements in order to maintain the balance of responses respectively: 1) Strongly disagree; 2) Disagree; 3) Neutral; 4) Agree; 5) Strongly agree. After reversing items that were negatively stated statements, the scores aggregated the result calculated from the median since study data were not normally distributed. Again, these results changed to dichotomous outcome; based on the cumulative score, respondents, who scored the median value of the total and above the median, were considered as having "positive attitude" towards emergency contraceptive while those scored below the median of the total were considered as having "negative attitude" towards emergency contraceptive.

The Practice of emergency contraceptive was any previous history of emergency contraceptive usage and the outcome was measured by their response (Yes or No).

\section{Data management and analysis}

Collected data was checked for completeness, coded and entered into EpiData version 3.1 and analyzed by SPSS 23.0. Descriptive statistics used to describe data by (mean, standard deviation, median, percentage, frequency) and logistic regression was used to identify factors associated with practice of emergency contraceptive. The $95 \%$ confidence interval was estimated and $\mathrm{P}<0.05$ was considered to be significant. Results displayed in tables and graphs as needed.

\section{Ethics statement}

Institutional Review Board (IRB) gave the written ethical approval for this study. 


\section{Results}

\section{Sociodemographic characteristics}

A total of 456 making $98.7 \%$ of response rate undergraduate female college students completed the overall questionnaire. The majority of the respondents were between the ages of 18-22 (85.3\%) years old and more than half $(61.5 \%)$ of them came from urban area in different divisions of the country with the average age $(\mathrm{M} \pm \mathrm{SD}=19.75$ \pm 1.812 ) ranged 15 -26 years old with 19.00 median as presented below (Table 1).

\section{Sexual behavior}

As showed in Table 2 below about $39.5 \%$, encountered unintended pregnancy and more than two-third (76.5\%) had history of induced abortion.

\section{Respondents' knowledge of emergency contraceptive}

Twelve questions were used to measure knowledge of the respondents on emergency contraceptive. The questionnaire specifically asked about the knowledge of emergency contraceptive as depicted in Table 3.

About $72.6 \%$ of the participants reported having heard about emergency contraceptive prior to the study.

\section{Awareness and source of emergency contraceptive}

The knowledge level of the study participants in this study were Table 1: Sociodemographic Characteristics of the respondents.

\begin{tabular}{|c|c|c|}
\hline Variable & Number & Relative frequency \\
\hline \multicolumn{3}{|l|}{ Age $(n=451)$} \\
\hline$<20$ & 227 & 50.3 \\
\hline $20-25$ & 223 & 49.5 \\
\hline$>25$ & 1 & 0.2 \\
\hline \multicolumn{3}{|l|}{ Place grew up $(n=454)$} \\
\hline Urban & 279 & 61.5 \\
\hline Rural & 175 & 38.5 \\
\hline \multicolumn{3}{|c|}{ High school field of study ( $n=456$ ) } \\
\hline Art student & 106 & 23.3 \\
\hline Science student & 350 & 76.7 \\
\hline \multicolumn{3}{|c|}{ University field of study $(n=455)$} \\
\hline Art student & 116 & 25.5 \\
\hline Science student & 208 & 45.7 \\
\hline Health science student & 131 & 28.8 \\
\hline \multicolumn{3}{|c|}{ Year of study at the university $(n=450)$} \\
\hline First & 132 & 29.3 \\
\hline Second & 120 & 26.7 \\
\hline Third & 73 & 16.2 \\
\hline Fourth & 104 & 23.1 \\
\hline Other(fifth year, six year) & 21 & 4.7 \\
\hline \multicolumn{3}{|l|}{ Boyfriend status ( $n=455)$} \\
\hline Yes & 131 & 28.8 \\
\hline No & 324 & 71.2 \\
\hline
\end{tabular}

Note: $\mathrm{n}$ : Complete data.
Table 2: Sexual behavior and pregnancy status of the respondent' about EC Practice.

\begin{tabular}{|l|c|c|}
\hline \multicolumn{1}{|c|}{ Variable } & Number & Relative Frequency \\
\hline Sexual activity (n=452) & & \\
\hline Yes & 49 & 10.8 \\
\hline No & 403 & 89.2 \\
\hline $\begin{array}{l}\text { History of unprotected sexual } \\
\text { intercourse }\end{array}$ & & \\
\hline Yes & 43 & 9.5 \\
\hline No & 129 & 28.5 \\
\hline History of unintended pregnancy & & \\
\hline Yes & 17 & 3.8 \\
\hline No & 157 & 34.7 \\
\hline Reason for unintended pregnancy & & \\
\hline Contraceptive failure & & 2.2 \\
\hline Forgot to take contraceptive & 10 & 0.4 \\
\hline Don't know about contraceptive & 2 & 3.3 \\
\hline History of induced abortion $^{\text {d }}$ & 15 & 2.9 \\
\hline Note: & 13 & (1) \\
\hline
\end{tabular}

Note: ${ }^{a-d}$ Only those who are sexually active answered the questions.

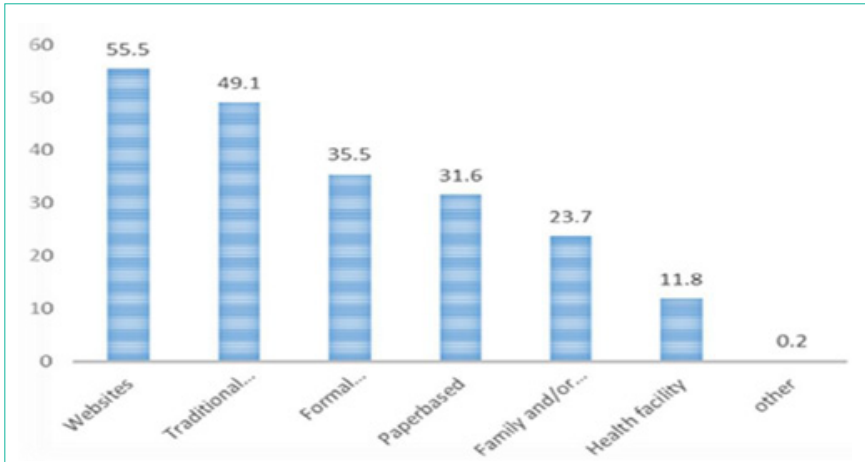

Figure 1: Source of Awareness of emergency contraceptive.

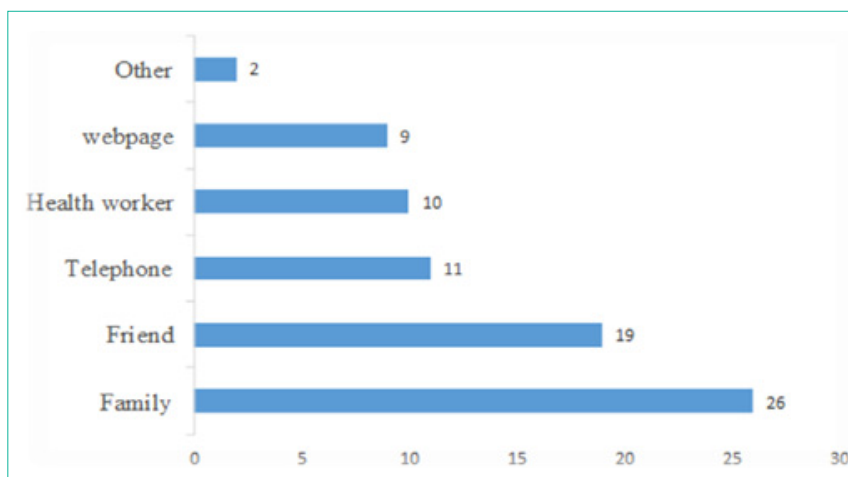

Figure 2: Source recommends used EC Multiple answer possible.

243(53.3\%) of them scored "good knowledge" about emergency contraceptive as presented below Figure 1.

\section{Respondents' attitude towards emergency contraceptives}

The attitude of the study participants towards emergency contraceptives was measured using 14 items rated on five-point Likert scale of six negatively and 8 positively stated statements in order to maintain the balance of responses respectively. The total attitude level 
Table 3: Knowledge of respondents who ever heard about Emergency Contraceptive?

\begin{tabular}{|c|c|c|}
\hline Variable & Number & $\begin{array}{l}\text { Relative } \\
\text { frequency }\end{array}$ \\
\hline Ever heard of emergency contraceptive & 331 & 72.6 \\
\hline \multicolumn{3}{|c|}{$\begin{array}{l}\text { Do you know where a woman (You) can obtain } \\
\text { emergency contraception? }\end{array}$} \\
\hline Yes & 243 & 53.3 \\
\hline No & 213 & 46.7 \\
\hline \multicolumn{3}{|c|}{ Which one is used as emergency contraceptive? } \\
\hline Oral contraceptive pills & 389 & 85.3 \\
\hline Intrauterine contraceptive device & 65 & 14.3 \\
\hline Condom & 253 & 55.5 \\
\hline Don't know & 39 & 8.6 \\
\hline \multicolumn{3}{|c|}{$\begin{array}{l}\text { Do you know emergency contraception is } \\
\text { important if condom breaks? }\end{array}$} \\
\hline Yes & 388 & 85.1 \\
\hline No & 9 & 2 \\
\hline Don't know & 59 & 12.9 \\
\hline \multicolumn{3}{|c|}{$\begin{array}{l}\text { When emergency contraceptive pill(s) can be used } \\
\text { effectively? }\end{array}$} \\
\hline Just before sexual intercourse & 89 & 19.5 \\
\hline Immediately after unprotected sex & 253 & 52 \\
\hline Don't know & 130 & 28.5 \\
\hline \multicolumn{3}{|c|}{$\begin{array}{l}\text { Does emergency contraceptive prevents sexually } \\
\text { transmitted infections (STI). }\end{array}$} \\
\hline Yes & 18 & 3.9 \\
\hline No & 354 & 77.6 \\
\hline Don't know & 84 & 18.4 \\
\hline \multicolumn{3}{|c|}{$\begin{array}{l}\text { Do you know emergency contraceptive can be } \\
\text { used as an abortifacient? }\end{array}$} \\
\hline Yes & 21 & 4.6 \\
\hline No & 338 & 74.1 \\
\hline Don't know & 97 & 21.3 \\
\hline \multicolumn{3}{|c|}{$\begin{array}{l}\text { Does emergency contraception used as a routine } \\
\text { contraceptive? }\end{array}$} \\
\hline Yes & 91 & 20 \\
\hline No & 289 & 63.4 \\
\hline Don't know & 76 & 16.7 \\
\hline \multicolumn{3}{|c|}{ Is using emergency contraceptive illegal in china? } \\
\hline Yes & 325 & 71.3 \\
\hline No & 18 & 3.9 \\
\hline Don't know & 113 & 24.8 \\
\hline \multicolumn{3}{|c|}{$\begin{array}{l}\text { Does emergency contraceptive pill(s) need a } \\
\text { prescription? }\end{array}$} \\
\hline Yes & 128 & 28.1 \\
\hline No & 165 & 35.7 \\
\hline Don't know & 163 & 36.2 \\
\hline \multicolumn{3}{|l|}{ Knowledge level(summary index) } \\
\hline Good knowledge & 243 & 53.3 \\
\hline Poor knowledge & 213 & 46.7 \\
\hline
\end{tabular}

result showed that about 256 (56.1\%) of study respondents showed a 'positive attitude' towards emergency contraceptive as showed in
Table 4.

Practice of emergency contraceptives among the respondents'

The practice of emergency contraceptive among the sexually active participants was $55.1 \%$. Majority of the respondents' ever used emergency contraceptive and family were the main source for the used method showed Figure 2.

\section{Predictors associated with the KAP of emergency contraceptive}

Logistic regression result showed that factors associated with knowledge of emergency contraceptive during analysis were field of study (AOR=0.53; 95\% CI $(0.31,0.91), \mathrm{p}=0.02)$, year of study $(\mathrm{AOR}=2.23 ; 95 \% \mathrm{CI}(1.20,4.14), \mathrm{p}=0.01)$ and awareness $(\mathrm{AOR}=0.19$; $95 \%$ CI $(0.10,0.36), \mathrm{p}<0.001)$. Similarly, this study result concluded that as age (AOR 3.99; 95\% CI $(2.35,6.78), \mathrm{p}<0.001)$ ], year of study (AOR $=0.09 ; 95 \% \mathrm{CI}(0.05,0.19), \mathrm{p}<0.001)$ and sexual behavior (AOR 0.43 ; $95 \%$ CI $(0.21,0.89), \mathrm{p}=0.02)$ were the significant predictors associated with attitude towards emergency contraceptive. Sexual behavior $(\mathrm{p}<0.001, \mathrm{AOR}=0.02 ; 95 \%$ CI $(0.01,0.07)$ and attitude $(\mathrm{p}=0.004, \mathrm{AOR}=5.29 ; 95 \% \mathrm{CI}(1.72,16.26)]$ towards emergency contraceptive were the predictors associated with the practice of emergency contraceptive as showed in Table 5.

\section{Discussion}

\section{Knowledge of emergency contraceptive}

The findings indicated that $72.6 \%$ reported ever heard about emergency contraceptive prior to the study which is consistent with the study in the university of Nigeria and northwest Pennsylvania $[19,20]$. Websites were the major source of information for $55.5 \%$ of female students, and this is inline with the study done in Germany among adolescents that recommended accurate knowledge is necessary for correct use of emergency contraceptive [21]. Only 14.3\% of study participants responded IUDs as emergency contraceptive but the interventional study result showed that users were counseled equally with other emergency contraceptive and the large majority continued to use the IUDs for ongoing contraception [22]. With regard, to when oral emergency contraceptive pill(s) could be used effectively, about (52.0\%) reported as "immediately after unprotected sexual intercourse" and this result is in line with the studies in the Journal of School Nursing and India [23,24].

More than two-third $71.3 \%$ of the study participants responded that using emergency contraceptive is illegal in china and only about $35.7 \%$ of the participants knew that a prescription is not required to obtain emergency contraceptive pills which is consistent with the European Medicine Agency that recommended the legality of emergency contraceptive and freely availability of EC without prescription in most European Union countries [25].

The study result on the general knowledge level indicated that about half $(53.3 \%)$ of study participants have good knowledge on emergency contraceptive. This result is in line with the study result found in Nigeria [26].

Knowledge of emergency contraceptive was significantly associated with field of study, year of study and awareness those remained significant during logistic regression analysis. It indicated 
Table 4: Attitudes towards emergency contraceptives among the respondents'.

\begin{tabular}{|c|c|c|c|c|c|c|}
\hline Variables & S. disagree $\%$ & Disagree\% & Neutral\% & Agree\% & S. agree $\%$ & Total \\
\hline Causes health problem & 1.3 & 1.3 & 11.6 & 43.9 & 41.9 & $100 \%$ \\
\hline Hurts the baby in case it does not work. & 2.4 & 1.8 & 23.6 & 33.8 & 38.4 & $100 \%$ \\
\hline Future pregnancy complications & 2.6 & 3.3 & 16.4 & 41.7 & 36 & $100 \%$ \\
\hline Sexual partner pressure & 9.2 & 13.6 & 49.8 & 18 & 9.4 & $100 \%$ \\
\hline Discourage consistent use of condoms & 32.5 & 37.3 & 22.4 & 3.5 & 4.3 & $100 \%$ \\
\hline Affect ongoing methods of contraception negatively. & 9.6 & 6.6 & 43.2 & 23.1 & 17.5 & $100 \%$ \\
\hline Recommend to a friend or relative in case of need. & 27.4 & 9.6 & 32.5 & 19.3 & 11.2 & $100 \%$ \\
\hline Safe for most women & 20 & 33.3 & 31.1 & 14.3 & 1.3 & $100 \%$ \\
\hline Recommend in case of unprotected sexual intercourse & 4.4 & 11.8 & 13.2 & 35.3 & 35.3 & $100 \%$ \\
\hline Recommend case of regular contraceptive mishap & 27.9 & 43.9 & 10 & 9.4 & 8.8 & $100 \%$ \\
\hline Recommend in case of rape & 11 & 16 & 5 & 35.1 & 32.9 & $100 \%$ \\
\hline Orientation & 0.7 & 1.1 & 4.8 & 31.1 & 62.3 & $100 \%$ \\
\hline Need on/in campus/college. & 7.9 & 16.2 & 10.5 & 21.5 & 43.9 & $100 \%$ \\
\hline Future use & 12.1 & 21.9 & 20.2 & 23.9 & 21.9 & $100 \%$ \\
\hline Summary index & \multicolumn{3}{|c|}{ Number } & \multicolumn{3}{|c|}{ Relative frequency } \\
\hline Positive attitude & \multicolumn{3}{|c|}{256} & \multicolumn{3}{|c|}{56.1} \\
\hline Negative attitude & \multicolumn{3}{|c|}{200} & \multicolumn{3}{|c|}{43.6} \\
\hline
\end{tabular}

Note: s-strongly.

Table 5: Factors associated with the Practice of Emergency Contraceptive.

\begin{tabular}{|c|c|c|c|c|}
\hline \multirow{2}{*}{ Variables } & \multicolumn{2}{|c|}{ Practice of EC } & \multirow{2}{*}{ COR $(95 \% \mathrm{Cl})$} & \multirow{2}{*}{ AOR $(95 \% \mathrm{Cl})$} \\
\hline & Yes & No & & \\
\hline \multicolumn{5}{|l|}{ Age } \\
\hline$<20$ years & $19(8.3)$ & 210(91.7) & $2.465(1.06,5.75)^{*}$ & $1.71(0.45,6.53)$ \\
\hline$\geq 20$ years & $8(3.5)$ & 218(96.5) & 1 & 1 \\
\hline \multicolumn{5}{|l|}{$\begin{array}{l}\text { Place of } \\
\text { residence }\end{array}$} \\
\hline Rural & 12(6.9) & 163(93.1) & $1.291(0.59,2.83)$ & $1.45(0.58,3.94)$ \\
\hline Urban & $15(5.4)$ & 263(94.6) & 1 & 1 \\
\hline \multicolumn{5}{|c|}{ Field of study } \\
\hline Art/science & $22(6.8)$ & 302(93.2) & $1.84(0.68,4.96)$ & $1.98(0.54,7.23)$ \\
\hline Health & $5(3.8)$ & $126(96.2)$ & 1 & 1 \\
\hline \multicolumn{5}{|c|}{ Level of study } \\
\hline Senior & $22(6.8)$ & 301(93.2) & $1.86(0.69,5.01)$ & $0.51(0.15,2.68)$ \\
\hline Junior & $5(3.8)$ & $127(96.2)$ & 1 & 1 \\
\hline \multicolumn{5}{|l|}{ Boyfriend } \\
\hline Yes & $17(13.0)$ & $114(87.0)$ & 1 & 1 \\
\hline No & $10(3.1)$ & $313(96.9)$ & $0.21(0.19,0.48)^{\star \star}$ & $0.55(0.19,1.59)$ \\
\hline \multicolumn{5}{|c|}{ Sexual behavior } \\
\hline Yes & 19(38.8) & $30(61.2)$ & 1 & 1 \\
\hline No & $8(2.0)$ & $394(98.0)$ & $0.03(0.01,0.08)^{\star \star}$ & $0.02(0.01,0.07)^{\star}$ \\
\hline \multicolumn{5}{|c|}{ Attitude level } \\
\hline Positive & $15(5.2)$ & 272(94.8) & 1 & 1 \\
\hline Negative & $12(7.1)$ & 156(92.9) & $1.39(0.64,3.06)$ & $5.29(1.72,16.26)^{*}$ \\
\hline \multicolumn{5}{|c|}{ Knowledge level } \\
\hline Good & $16(6.6)$ & 227(93.4) & 1 & 1 \\
\hline Poor & $11(5.2)$ & 201(94.8) & $0.78(0.35,1.71)$ & $1.61(0.54,4.75)$ \\
\hline
\end{tabular}

Note: **significant at $p<0.001$, "significant at $p<0.05$, AOR: Adjusted Odds Ratio;

Cl: Confidence Interval; COR: Crude Odds Ratio; EC: Emergency Contraceptive. that those respondents who were studying art and/or other science were $(46.8 \%)$ less likely to have good knowledge [(AOR=0.53; $95 \%$ CI $(0.31,0.91), p=0.022)]$ about emergency contraceptive than health science. Senior year students had more knowledge [(AOR=2.23; 95\% CI $(1.20,4.14) \mathrm{p}=0.011)]$ about emergency contraceptive than junior students and respondents those who have not ever heard of EC were (80.9\%) less likely to have a knowledge about EC [(AOR=0.19; 95\% CI $(0.10,0.36), \mathrm{p}<0.001)]$.

\section{Sexual characteristics and attitude towards emergency contraceptive}

This study showed that only $10.8 \%$ of the respondents were sexually active which is consistent with the study done in Beijing among female college students that only $10.5 \%$ of them were sexually active [27]. This study identified that among the sexually active respondents $87.8 \%$ of them practiced unprotected sexual intercourse, which might be risk for unintended pregnancy and sexually transmitted infections. Similarly, unsafe sexual practices are common among young adults especially in universities and other higher educational institutions and prevention of unintended pregnancy are necessary measures to maintain good health among university students $[28,29]$. Almost half $(45.8 \%)$ of the female students showed a positive attitude towards the use of emergency contraceptive as they would use it in the future if required and $30.5 \%$ would recommend it to others which is comparable with the result found in Ethiopia [18]. The study finding showed almost all $93.4 \%$ of study participants indicated that emergency contraceptive's information should be included in the university orientation program and about two-third (65.4\%) of the participants need if it provided on the campus. This study result is somewhat lower with the study done in South Africa [17]. This indicates that the students are interested in learning more about emergency contraceptive and that the university management, faculty and department will address this issue. The study findings 
showed that about (56.1\%) of the study respondents' had positive attitude towards emergency contraceptive that is comparable with the study in Ethiopia and Nigeria [26,30].

The study result concluded that as age [(AOR 3.99; 95\% CI $(2.35$, $6.78), \mathrm{p}<0.001)$ ], year of study [(AOR 0.09; 95\% CI $(0.05,0.19)$, $\mathrm{p}<0.001]$ and sexual behavior [(AOR $=0.43$; $95 \%$ CI $(0.21,0.89)$, $\mathrm{p}=0.023$ ] were the significant predictors of the study participant's attitude towards emergency contraceptive. This means the study reported that the participants below 20 years old were 4 times more likely to have positive attitude towards emergency contraceptive. Senior students who responded the questionnaire were $90.0 \%$ less likely to have positive attitude towards EC. Sexually active participants were $57.0 \%$ less positive attitude towards emergency contraceptive.

\section{Practice of emergency contraceptive}

Among the sexually active participants about (55.1\%) ever used emergency contraceptive, which is comparable with the study in Tanzania [31]. In addition, high level of contraceptive knowledge does not translate into actual practice in this study or from other studies. This study also showed that majority of study participants those who used emergency contraceptive were recommended by their family, which is consistent with the study in Australia, China and University of Hong Kong [32-34]. Almost half of the respondents lack good knowledge on the method of EC and in addition ever use of EC is low compared to unprotected sexual intercourse. The lack of knowledge of its use and health risks, concerns associated with cultural and societal beliefs, and misconceptions about its utilization could be the reasons for the low usages [35].

Sexual behavior and attitude level towards emergency contraceptives were the predictors associated with the practice of emergency contraceptive. This means respondents' those who were sexually inactive were $98.0 \%$ less likely to use emergency contraceptive $(\mathrm{p}<0.001, \mathrm{AOR}=0.02 ; 95 \% \mathrm{CI}(0.01,0.07))$ and respondents' who showed negative attitudes were 5 times more likely to use emergency contraceptive than those who showed positive attitude towards the practice of emergency contraceptive $(\mathrm{p}=0.004, \mathrm{AOR}=5.29 ; 95 \% \mathrm{CI}$ $(1.72,16.26)$ This is consistent with the studies in China and Curacao $[36,37]$. The vulnerability of young women of no formal education about emergency contraception tends to dominate the disclosure on unplanned pregnancy and abortion both in developing and developed countries. The study done in china by Mao and colleagues concluded that young women of reproductive age have low awareness of contraception. The weakness of the study touches on sensitive issues because of that the possibility of underestimation can't be excluded even though the study was anonymous. As its strength, this study identified that the self-reported sexual activities of respondents clearly reinforce the need for emergency contraceptives and there is a need to empower young people to discuss sexual and reproductive health issues with their parents, friends, relatives and others. At the government level, Communication about reproductive health service should be supported. All health care providers in clinical and community should be committed themselves to providing pre and post-abortion family planning counseling and complete care to every woman including students. Strengthening information, education and communication in the university on sexual reproductive health with special emphasis on different emergency contraceptive will be a problem solving procedure. As this study implied the self-reported sexual activities of respondents clearly reinforce the need for emergency contraceptives and about 426(93.4\%) of them responded emergency contraceptive's information's should be included in the university orientation program and almost two-third of the participants need if it provided on the campus. This study finding indicated that attitude towards the practice of emergency contraceptive among female college students was opposite and future study needed to include both graduate and male students too.

\section{Conclusion}

Knowledge and attitude level of study participants were marginally about half. However, utilization of emergency contraceptive even among the sexually active participant was low compared to the number of unprotected sexual intercourse and unintended pregnancy and abortion was high. The knowledge level, attitude towards and practice of emergency contraceptives of study participants were affected by age, field of study, level of study, awareness and sexual behavior.

\section{Acknowledgement}

The authors would like to acknowledge the contributions of research assistants both the management institutions and participants of the study.

\section{Funding}

The study was funded by Ministry of Commerce of China but the funding body has no role in the design of the study and data collection, analysis, and interpretation of data and in writing the manuscript.

\section{References}

1. Davis AR, Praditpan P. Emergency Contraception: Two Steps Forward, One Step Back. Semin Reprod Med. 2016; 34: 152-158.

2. Koyama A, Hagopian L, Linden J. Emerging options for emergency contraception. Clinical medicine insights Reproductive health. 2013; 7: 23-35.

3. Lopez LM, Bernholc A, Chen M, Tolley EE. School-based interventions for improving contraceptive use in adolescents. Cochrane Database Syst Rev. 2016: CD012249

4. Sedgh G, Finer LB, Bankole A, Eilers MA, Singh S. Adolescent Pregnancy, Birth, and Abortion Rates Across Countries: Levels and Recent Trends. Journal of Adolescent Health. 2015; 56: 223-230.

5. Jatlaoui TC, Curtis KM. Safety and effectiveness data for emergency contraceptive pills among women with obesity: a systematic review. Contraception. 2016; 94: 605-611.

6. Wang $\mathrm{H}$, Long L, Cai $\mathrm{H}, \mathrm{Wu} \mathrm{Y}, \mathrm{Xu} \mathrm{J}$, Shu C, et al. Contraception and unintended pregnancy among unmarried female university students: A crosssectional study from china. PloS one. 2015; 10: e0130212.

7. Shu C, Fu A, Lu J, Yin M, Chen Y, Qin T, et al. Association between age at first sexual intercourse and knowledge, attitudes and practices regarding reproductive health and unplanned pregnancy: a cross-sectional study. Public Health. 2016; 135: 104-113.

8. Oringanje C, Meremikwu MM, Eko H, Esu E, Meremikwu A, Ehiri JE. Interventions for preventing unintended pregnancies among adolescents. Cochrane Database of Systematic Reviews. 2016.

9. Zhou Y, Xiong C, Xiong J, Shang X, Liu G, Zhang M, et al. A blind area of family planning services in China: unintended pregnancy among unmarried graduate students. BMC Public Health. 2013; 13: 1-8.

10. Corbelli J, Bimla Schwarz E. Emergency contraception: a review. Minerva Ginecol. 2014; 66: 551-564. 
11. Zhang D, Yan MX, Ma J, Xia W, Xue RH, Sun J, et al. Association between knowledge about levonorgestrel emergency contraception and the risk of ectopic pregnancy following levonorgestrel emergency contraception failure: a comparative survey. Pharmacoepidemiology and drug safety. 2016; 25 : 880-888

12. Cleland K, Raymond EG, Westley E, Trussell J. Emergency contraception review: evidence-based recommendations for clinicians. Clin Obstet Gynecol. 2014; 57 : 741-750

13. Trussell J, Raymond EG, Cleland K. Emergency contraception: a last chance to prevent unintended pregnancy. Contemp Readings L \& Soc Just. 2014 6: 7-38.

14. WHO. Making health services adolescent friendly. Developing national quality standards for adolescent friendly health services. Geneva: WHO. 2012.

15. Darteh EK, Doku DT. Knowledge and Usage of Emergency Contraceptives among University Students in Ghana. J Community Health. 2016; 41: 15-21.

16. Arinze-Onyia SU, Aguwa EN, Nwobodo E. Health education alone and health education plus advance provision of emergency contraceptive pills on knowledge and attitudes among university female students in Enugu, Nigeria. Nigerian journal of clinical practice. 2014; 17: 100-105

17. Hoque ME, Ghuman S. Knowledge, Practices, and Attitudes of Emergency Contraception among Female University Students in KwaZulu-Natal, South Africa. PLoS ONE. 2012; 7: e46346.

18. Ahmed FA, Moussa KM, Petterson KO, Asamoah BO. Assessing knowledge attitude, and practice of emergency contraception: a cross- sectional study among Ethiopian undergraduate female students. BMC Public Health. 2012; 12: 110 .

19. Miller LM. College student knowledge and attitudes toward emergency contraception. Contraception. 2011; 83: 68-73.

20. Abiodun O. Use of emergency contraception in Nigeria: An exploration of related factors among sexually active female university students. Sexua \& reproductive healthcare: Official journal of the Swedish Association of Midwives. 2016; 7: 14-20.

21. Denis L, Storms M, Peremans L, Van Royen K, Verhoeven V. Contraception: a questionnaire on knowledge and attitude of adolescents, distributed on Facebook. International journal of adolescent medicine and health. 2016; 28 : 407-412.

22. Kohn JE, Nucatola DL. EC4U: results from a pilot project integrating the copper IUC into emergency contraceptive care. Contraception. 2016; 94: 4851.

23. Joseph N, Shetty B, Hasreen F, Ishwarya R, Baniya M, Sachdeva S, et al. Awareness and Attitudes Toward Emergency Contraceptives Among College Students in South India. J Obstet Gynecol India. 2016; 66: 363-369.

24. Adamji JM, Swartwout K. Advance provision of emergency contraception for adolescents. J Sch Nurs. 2010; 26: 443-449.
25. Italia S, Brand H. Status of Emergency Contraceptives in Europe One Year after the European Medicines Agency's Recommendation to Switch Ulipristal Acetate to Non-Prescription Status. Public Health Genomics. 2016; 19: 203210.

26. Ezebialu I, Eke A. Knowledge and practice of emergency contraception among female undergraduates in South eastern Nigeria. Ann Med Health Sci Res. 2013; 3: 541-545.

27. Zhou Y-Z, Zhang M-M, Wei S, Guan H-T, Yin P, Ren N, et al. [Survey on knowledge, attitude, practice related to contraception among college students in Beijing]. Zhonghua Liu Xing Bing Xue Za Zhi. 2009; 30: 710-712.

28. Rutherford GW, Anglemyer A, Bagenda D, Muyonga M, Lindan CP, Barker $\mathrm{JL}$, et al. University students and the risk of HIV and other sexually transmitted infections in Uganda: the Crane survey. Int J Adolesc Med Health. 2014; 26 : 209-215

29. Bayrami R, Javadnoori M. Comparison of the contraceptive use and its related factors among women seeking repeat and first-time induced abortions in Iran. Nurs Midwifery Stud. 2015; 4: e17529.

30. Abate M, Assefa N, Alemayehu T. Knowledge, Attitude, Practice, and Determinants Emergency Contraceptive Use among Women Seeking Abortion Services in Dire Dawa, Ethiopia. PloS one. 2014; 9: e110008.

31. Somba MJ, Mbonile M, Obure J, Mahande MJ. Sexual behaviour contraceptive knowledge and use among female undergraduates' students of Muhimbili and Dar es Salaam Universities, Tanzania: a cross-sectional study. BMC women's health. 2014; 14: 94

32. Chi X. A study on sexual health knowledge, sexual attitudes and sex related behaviors of university students in Hefei, China. 2014

33. Wang N. Parent-Adolescent Communication about Sexuality in Chinese Families. Journal of Family Communication. 2016; 16: 229-246.

34. Morawska A, Walsh A, Grabski M, Fletcher R. Parental confidence and preferences for communicating with their child about sexuality. Sex Education. 2015; 15: 1-14.

35. Kistnasamy EJ, Reddy P, Jordaan J. An evaluation of the knowledge, attitude and practices of South African university students regarding the use of emergency contraception and of art as an advocacy tool. South African Family Practice. 2009; 51: 423-426.

36. Zeng YC, Luo TZ, Zhou Y. Relationships between attitudes toward sexuality sexual behaviors, and contraceptive practices among Chinese medical and nursing undergraduates. Nurs Health Sci. 2015; 17: 287-292.

37. van den Brink MJ, Boersma AA, Meyboom-de Jong B, de Bruijn JG. Attitude toward contraception and abortion among Curacao women. Ineffective contraception due to limited sexual education? BMC family practice. 2011; 12: 55 